\title{
O piano matemático
}

\section{The mathematical piano}

\author{
Dorinda Mato-Vázquez, Rocío Chao-Fernández, Aurelio Chao-Fernández \\ Universidade da Coruña
}

\begin{abstract}
Resumo
No contexto educativo estase a poñer moita énfase na interdisciplinariedade, na educación emocional, nas actitudes ou na motivación do alumnado. Porén, o noso sistema educativo adoece dunha preocupante falta de formación do profesorado nestes aspectos, nas propostas e materiais didácticos específicos para o ensino e na disposición de interrelacionar as diversas áreas do currículo. Neste traballo lévase a cabo unha proposta didáctica interdisciplinar para desenvolver nos escolares de Educación Infantil as capacidades musicais e matemáticas. A interacción de ambas as materias axúdalle ao alumnado a asociar exitosamente os conceptos de ambas as disciplinas e a acadar unha educación integral e non fragmentada. Palabras clave: música, matemáticas, educación infantil, interdisciplinariedade, actividades.
\end{abstract}

\begin{abstract}
The interdisciplinary approach has gained interest in the educational context for the emotional education, attitudes and motivation of students. However, Spanish Education System suffers from a serious lack of teacher training in proposals and specific instructional materials for teaching and willingness to interrelate the various areas of the curriculum. In this research, an interdisciplinary didactic proposal is carried out in order to develop in musical and mathematical abilities of Early Childhood students due to the interaction of both subjects The benefits of working an interdisciplinary song in math are innumerable and can help students succeed in associating concepts from both disciplines, achieving a comprehensive education.

Keywords: music, maths, childhood education, interdisciplinary, activities.
\end{abstract}

\section{Introdución}

As matemáticas nacen da necesidade de rexistrar o paso do tempo. Nun principio tan só eran números e conteos para o gando, as colleitas e as operacións matemáticas (Mankiewicz, 2000).

A día de hoxe, todos estamos preocupados sobre como motivar os «estudantes», pois, a pesar da importancia que se lle atribúe na nosa sociedade, segue a ser unha inquedanza elevar o nivel de interese, gusto e logros coa matemática. Convén iniciar desde a etapa de Educación Infantil esta motivación.

Pola súa parte, a música xorde coa finalidade de protexerse de certos fenómenos naturais, de atraer a axuda dos deuses, de festexar diferentes celebracións... (Pascual Mejía, 2006).

Pero, no contexto actual, a música é unha das materias máis esquecidas, aínda que sexa unha área de ensino excelente para a formación dos suxeitos. Particularmente, contribúe á adquisición de conceptos lóxico-matemáticos nesta etapa educativa onde a manipulación, a experimentación e o xogo se tornan en grandes fontes de aprendizaxe.

$O$ primeiro en falar da interacción de ambas foi Pitágoras (Peralta, 2011), ao decatarse de que a música, como medio de comunicación, podía ser medida por medio de razóns de números enteiros, comprobando que ao dividir unha corda en determinadas proporcións, podía producir sons pracenteiros para o oído.

Segundo a lenda, ao pasar por unha ferraría, Pitágoras escoitou o son que facían os ferreiros ao golpear sobre as zafras. Por algunha razón, ese concerto de marteladas ás veces soaba musical e ás veces non. Ao volver á súa casa, Pitágoras comezou a experimentar con cordas de distinta lonxitude e atopou que o son musical se obtiña cando a relación entre as súas lonxitudes se expresaba mediante números pequenos: unha o dobre de longa que a outra, ou o triplo, ou dous terzos, ou algunha relación similar (Pastor Martín, 2008). Como a frecuencia dos sons que emite unha corda depende, igual que outras condicións, da súa lonxitude, o que Pitágoras atopara é a relación de frecuencia que, sabemos agora, define o carácter musical dun son (Edo, 2012).

A Pitágoras impresionoulle tanto que unha relación numérica permitira definir algo tan subxectivo como a diferenza entre o ruído e a música que parece que foi alí cando dixo que "os números gobernan o mundo». Polo menos, gobernaban na música. Non é casual que, na antiga Grecia, a música fora unha rama da matemática, xunto á aritmética, a xeometría e a astronomía (Levitin, 2011).

Hoxe en día sabemos que o son que produce unha corda depende do seu grosor, lonxitude e tensión (Barberá, 2012). Para conseguir unha melodía coherente, reafirmarase unha secuencia de sons constantemente, pero evitando a monotonía e usando técnicas baseadas no plano xeométrico.

O certo é que, desde a antigüidade, as matemáticas e a música estiveron ligadas.

Moitos anos máis tarde, durante o Renacemento e o Clasicismo, os principais descubridores da unión entre elas fusionaron conceptos. Estes foron os músicos clásicos, sendo un dos máis importantes Bach, o cal compuxo moitas das súas obras cunha lóxica xeométricomusical, grazas á cal pensaba que o seu éxito estaría 
asegurado (Moreno, en Chao-Fernández, Mato-Vázquez e Chao-Fernández, 2015).

En 1993, Rayscher e colaboradores da Universidade de California publicaron os resultados obtidos nunha investigación realizada con grupos de estudantes universitarios, aos que puxeron a escoitar durante uns minutos unha sonata de Mozart, logrando puntuacións altas nas probas de habilidades viso-espaciais e cognitivas en xeral, así como un incremento transitorio do cociente intelectual. Este feito denominouse «efecto Mozart» (Casals, Carrillo e González-Martín, 2014). Estudos posteriores demostraron que escoitar a música de Mozart desencadea cambios de conduta (en relación con estados de alerta e calma), afectividade (induce estados emotivos) e metabólicos (aumento do contido de calcio e dopamina no cerebro) (Gómez, 2012).

Hoxe en día, é ben coñecida a estreita relación que gardan as matemáticas e a música, xa que as pautas que se utilizan son similares, igual que ocorre coa linguaxe.

As notas combínanse para formar patróns musicais como os números se combinan para crear diferentes solucións numéricas, e o noso cerebro procesa a dita información dunha maneira diferente que se se tratase doutra información calquera. Desde que nacemos sentímonos atraídos polas melodías rítmicas, e as voces dos adultos adáptanse a patróns melódicos e matematicamente pausados cando se dirixen aos bebés, e estes enseguida centran a súa atención neses sons (Akoschky, Alsina, Díaz e Giráldez, 2008).

Soamente temos que tapar os oídos e descubrilos de novo para comprobar que estamos rodeados de sons; e capaces todos eles de crear música. Cos sons e por tanto coa música, poderase aprender o concepto de ritmo, que xorde da duración do son; da melodía, que nace da diferente altura; da dinámica, que deriva da intensidade con que se produce; e da cor, que emerxe do timbre do son. Todos eles conforman as diferentes obras musicais (Conde, Martín e Viciana, 2002).

O ritmo atópase no movemento; por exemplo, cando camiñamos unhas veces amodo e outras máis rápido estamos creando diferentes ritmos, tamén cando cepillamos os dentes, cando nos peiteamos...

De igual xeito, podemos crear o noso propio ritmo golpeando un bolígrafo contra a mesa e logo pasándoo ao longo das arandelas dun caderno. Se lle damos a un cativo ou a unha cativa un obxecto que poida coller coas súas mans, comezará a crear patróns musicais e ritmos. Tamén lles axuda aos meniños/as a desenvolver a habilidade de comparar, que máis adiante lles servirá para clasificar (Mankiewicz, 2000).

A melodía dunha canción conséguese cantaruxándoa sen letra, repetindo unha sílaba como por exemplo, na, na, na.

A dinámica é o conxunto de sons fortes e suaves. Así, cando imitamos o son dunha locomotora, o que facemos é combinar un son forte chu-chu, seguido doutros sons suaves, chucuchuchu-chucuchuchu, esa sería a dinámica do son dunha locomotora.

Coa combinación de diferentes instrumentos e voces, o que conseguimos é unha gran variedade de cores; xa que o timbre de cada instrumento posúe unha cor. Por tanto combinando varios instrumentos conseguiranse máis cores (Fernández-Carrión, 2011).

\section{Metodoloxía}

Nesta investigación imos deseñar, aplicar e analizar unha proposta interdisciplinar de Matemáticas e Música con 25 alumnos/as de 5 anos dunha aula dun centro da Coruña de Educación Infantil. Tamén tataremos de salientar a importancia equitativa das dúas materias no desenvolvemento dos cativos e cativas, a súa capacidade formativa e como é doado traballar de forma interdisciplinar Matemáticas e Música desde as primeiras idades. Así, o valor das figuras, a escala musical, as calidades do son, a discriminación auditiva ou o establecemento de correspondencias de sons ofrécense como algúns dos contidos para traballar nas distintas actividades que propoñemos.

Así mesmo, pretendemos dar resposta á necesidade que xorde nos mestres e mestras desta etapa de ter que buscar alternativas innovadoras que sirvan para o desenvolvemento integral infantil.

\section{Procedemento}

Acórdase coa docente levar a cabo a proposta de actividades dous días á semana no mes de novembro procurando non distorsionar as rutinas de aula.

Organizamos os nenos e as nenas ao azar e dividímolos en 5 grupos de 5 membros cada un, aínda que haberá actividades en que se xogue nun grupo grande, e entre toda a clase terán que conseguir realizar ou responder ao que se lles pide en cada cuadrícula.

O xogo consiste nun taboleiro de cartolina e plastificado con forma de teclado de piano, as cuadrículas son as teclas e os diferentes instrumentos que se atopan repartidos por el. Todas elas colocadas con velcro sobre o taboleiro para facilitar que se despeguen cada vez que se caia nelas. Cada cuadrícula leva escrito pola parte de atrás a actividade que se debe realizar ou a pregunta a que se debe responder, indicando tamén se se leva a cabo en grupos pequenos ou nun grupo grande.

As actividades ou preguntas explícanse con maior detemento nunha serie de tarxetas de cartolina plastificadas que se atopan sobre o taboleiro e que se corresponden con cada unha das cuadrículas. A temática versa sobre a música e as matemáticas en xeral e os instrumentos, de maneira que se traballen todos os contidos e obxectivos que se pretenden conseguir.

Para comezar a xogar, os cativos e cativas colocaranse en círculo, en pequenos grupos sobre a alfombra da asemblea, ao redor do taboleiro e elixirán unha das fichas de plastilina con forma de instrumento para cada equipo. Tirarán o dado en cada grupo pequeno, e quen obteña a maior puntuación comezará a partida e continuarán no sentido das agullas do reloxo. $\mathrm{O}$ grupo que percorra $\mathrm{o}$ xogo primeiro, será o que gañe, aínda que iso non condicionará que o resto dos xogadores continúen a xogar. Cada vez que un grupo gañe, os seus membros pasarán a formar parte do resto dos grupos que aínda seguen xogando (de maneira repartida ao azar). Desta forma, o xogo rematará co grupo completo da clase formando un mesmo equipo. 


\section{Proposta didáctica}

\section{Obxectivos}

-Adquirir destrezas e habilidades manipulativas aplicándoas ao manexo de útiles e materiais presentes no seu contorno/Aprender a manexar instrumentos Orff e obxectos do seu contorno.

-Iniciarse no control do propio comportamento relacionando a identificación das emocións e os intereses coa interiorización das normas e valores sociais.

-Establecer relacións causa-efecto, percibindo as consecuencias das súas accións nos obxectos ou persoas do seu contorno/indagar e experimentar cos elementos do contorno próximo.

-Establecer relacións de confianza, afecto, colaboración e pertenza baseándoas no respecto ás persoas e ás normas da sociedade.

-Utilizar as diversas linguaxes entendéndoas como instrumento de comunicación entre as persoas, de expresión das ideas e sentimentos e de representación da realidade.

-Sentir o feito musical identificándoo como un medio de expresión e manifestación cultural.

\section{Contidos}

- Potenciación das destrezas e habilidades na manipulación de instrumentos, ferramentas e materiais.

- Utilización dos instrumentos musicais e obxectos do seu contorno para producir diferentes sons.

- Vivencia e control do corpo en relación co movemento, coas dimensións do espazo e co movemento dos demais.

- Control do seu corpo para producir diferentes sons e dos movementos que pode facer ao ritmo da música.

- Fomento da capacidade de escolla entre varias alternativas, asumindo as consecuencias das propias accións.

- Construción de nocións temporais/Relación dos conceptos de espazo e de tempo e ritmo musical.

- Sentimento de pertenza aos grupos máis próximos e actitude de respecto e valoración cara ás outras persoas.

- Recoñecemento e utilización das posibilidades do corpo para comunicar.

- Utilización do movemento e da danza como medios de expresión.

- Comunicarse axeitadamente.

- Uso axeitado dos instrumentos musicais, obxectos e do propio corpo para emitir sons.

- Recoñecemento de sons do contorno natural e social.

- Gusto por participar co resto dos compañeiros en xogos musicais.

\section{Actividades}

\section{Encontra a parella}

Colócanse na mesa as tarxetas do revés, cara a abaixo. Nelas escóndense diferentes imaxes de instrumentos. Cada instrumento ten a súa parella idéntica. Os rapaces teñen que ir levantando as tarxetas dunha en unha e emparellándoas. Se non a encontran deixan a carta outra vez no mesmo lugar e cara a abaixo para que o seguinte rapaz probe sorte. Se atopan a parella retirarana da mesa deixando o resto colocado no mesmo lugar, favorecendo o exercicio de memoria visual.

O xogo rematará cando xa non queden cartas na mesa. Outra opción que se poderá facer é cambiar a temática das tarxetas, por exemplo con claves musicais, con personaxes de contos, con letras ou números... de modo que servirá para tratar calquera temática de todas as áreas de desenvolvemento mentres se favorece a memoria, a atención e a concentración.

\section{Cantaruxa a canción}

Comezará cantaruxando unha canción coñecida polos nenos, a propia docente, mentres os rapaces intentan adiviñar de cal se trata.

A continuación un membro do grupo que está xogando terá que cantaruxar outra e o resto adiviñala. Poderase facer unha canción por cada membro. A condición é manter o compás e o ritmo da canción orixinal mentres a cantaruxamos; favorecendo a adquisición de series de sons, secuenciacións, a atención, a memoria e o desenvolvemento auditivo. Algunhas cancións serían: Debaixo dun botón; Que chova, que chova!; Eu non sei; Collín, collín, collín; o cocherito leré; Había unha vez un barquiño etc.

\section{Labirinto}

Nesta actividade o/a neno/a debe seguir co dedo o camiño correcto para unir a figura musical co seu silencio correspondente. Estes xogos favorecen a visión espacial, o desenvolvemento visomotor (ollo-man), a lóxica, a resolución de problemas, a atención e a concentración.

\section{Duración do son}

O/a docente tocará diferentes instrumentos e os rapaces terán que saber que sons duran máis tempo e cales menos. Estes instrumentos serán unha frauta, unha pandeireta, o xilófono, o triángulo, as craves e as maracas.

Para que o exercicio sexa sinxelo, darase un só golpe de son con cada dous instrumentos escollidos ao azar.

Deste xeito estaremos traballando a discriminación auditiva, os conceptos longo e curto, a atención e a concentración.

\section{Imítame}

O/a docente producirá un son con algunha parte do corpo ou algún obxecto que teñamos na aula, e o resto imitarao (non se poderá utilizar ningún instrumento musical).

Así, ademais do ritmo, traballarase a memoria e a atención, a discriminación auditiva, a creatividade e a imaxinación.

\section{A tocar!}

O grupo de estudantes interpretará unha partitura, primeiro con percusión corporal, e posteriormente con instrumental Orff. Este exercicio permite desenvolver a capacidade de lóxica, a retención e a memoria, o ritmo e a atención.

\section{Recoñecendo instrumentos}

Producirán diferentes sons con varios instrumentos desde o ordenador. Os/as alumnos/as teñen que sinalar a 
imaxe do instrumento que soa no ordenador e que se encontra na clase e dicir o seu nome (tambor, paus, triángulo, xilófono, frauta, maracas, pandeireta e guitarra).

Seguirán a traballar a atención, a memoria e a discriminación auditiva.

\section{Orquestra}

Este xogo consiste en converterse en músicos dunha orquestra, para iso un dos membros dará palmas, outro pisará cos pes taconeando, outros dous farán un ruído coa boca e outro golpeará algún obxecto da clase.

Cada escolar debe manter un ritmo constante que marcará a mestra ao principio. Deste xeito terán que agudizar o seu oído, concentrarse e manter o seu ritmo e o son sen se deixar contaxiar polo que está ao lado facendo outro son diferente e a outro ritmo. Traballarán así a concentración, o ritmo e o compás, a atención e o conteo mental, que favorecerá manter un compás concreto.

\section{Música lenta e rápida}

Buscaremos música con diferentes ritmos e tempos, deste xeito cando os alumnos/as escoiten unha canción rápida, indicarémoslles que se movan rápido, e cando a canción sexa lenta moveranse amodo. Unha variante, se non temos música, podería ser cantaruxando unha canción a diferentes velocidades e dicirlles que se movan rápido ou amodo de acordo co ritmo da canción. Esta actividade fomentará a habilidade de escoitar activamente, e relacionar o movemento co que escoitan.

\section{Adiviña que soa}

Mirando un diario ou unha revista, deteranse naquelas fotos que conteñan imaxes que faciliten reproducir o son (tren, can, chuvia, animais etc.). Logo pediráselles que intenten facer eses sons coa súa voz, o seu corpo ou algún elemento ou obxecto da aula.

\section{Así soa o meu obxecto}

Presentando varios obxectos cotiáns diferentes en material e forma, proporáselles que recoñezan cada un deles polo seu son particular mentres observan o elemento. Logo, o/a docente ocultarase cos obxectos e faraos "soar» para que os nenos descubran de que obxecto se trata. Tamén lle poderá pedir a algún neno ou nena que sexa quen dea a volta e produza os sons para o resto de compañeiros e compañeiras.

\section{A banda e os silencios}

Formaremos unha «banda» ou «orquestra» de instrumentos non convencionais. O/a docente dirixirá o grupo para indicar cando tocan e cando non e que instrumentos soan ou se manteñen en silencio.

\section{Ritmo...e a tocar!}

A/o docente poñerá ou tocará unha canción e os nenos terán que seguir o mesmo ritmo cun instrumento musical. As cancións adaptaranse ao nivel dos nenos, e variarán en ritmo, compás e estilo musical.

\section{De que cor é a música}

Tras ver o videoclip Fantasía, de Disney, en que aparecen diferentes tipos de música, intensidades, ritmos e imaxes, pintarán o que lles suxeriu a música.

\section{A aplaudir!}

Os/as nenos/as terán que dicir nomes de conceptos musicais, matemáticos ou da categoría que elixan (cada vez que caina nesa cuadrícula poden elixir unha diferente para facelo variado) dando unha palmada en cada sílaba.

\section{Quen toca?}

Cada estudante ten un obxecto ou instrumento distinto. $\mathrm{O} / \mathrm{a}$ mestre de costas ao estudantado fará soar un deles e o neno que o teña igual, tocará o seu.

\section{Adiviña quen fala}

Os estudantes pecharán os ollos, mentres a profesora tocará a un deles, que os abrirá e terá que dicir unha palabra en voz alta para o resto dos seus compañeiros. Cando termine abrirán os ollos e terán que adiviñar de quen era esa voz.

\section{Cantas sílabas?}

Os/as alumnos/as terán que dar un golpe por cada sílaba da frase, ben cun instrumento musical ou sobre unha superficie. O resto dos alumnos/as, axudándose uns aos outros, deberán polo número de sílabas, adiviñar de que frase se trata.

- Te-mos un pa-xa-ro (6)

- Gus-ta- me can-tar (5)

- Te-ño frí-o (4)

- O -la (2)

\section{Avaliación}

Para realizar a avaliación, farase unha observación atendendo aos seguintes ítems:

- Segue o ritmo co seu corpo ou cos instrumentos.

- Interpreta co seu corpo os cambios de velocidade da música que escoita.

- Comprende a diferenza entre termos opostos como rápido/lento ou cerca/lonxe.

- Discrimina diferentes ritmos.

- É capaz de se expresar a través da música.

- Relaciona o ritmo da música co movemento corporal.

- Improvisa con diferentes instrumentos musicais, recursos espaciais e corporais.

- Agrupa obxectos en función da súa cor e tamaño.

- Coñece a diferenza entre os conceptos rápido/lento.

- Identifica a imaxe e sabe aplicar a acción correspondente.

- Controla a intensidade dos movementos que ten que levar a cabo.

- Segue a orde das secuencias.

- É capaz de memorizar as diferentes imaxes.

- Expresa emocións a través de movementos corporais.

\section{Resultados}

A docente levou a cabo a avaliación mediante a observación diaria, o que posibilitou analizar o proceso 
diario de cada un dos/as estudantes, as dificultades achadas e os cambios puntuais na realización das tarefas.

Con respecto ás actividades comentounos que foron motivadoras, axeitadas á idade dos nenos e propias para desenvolver os obxectivos programados en música e en matemáticas.

A metodoloxía de cada unidade, a propia práctica docente, o tempo e os materiais utilizados foron axeitados; o que procurou o éxito da proposta.

As aprendizaxes adquiridas e o ritmo de cada discente foi persoal e marcouno cada neno conforme ás súas características.

Alcanzáronse os obxectivos de cada materia ao $100 \%$.

Logrouse que comprenderan o valor das figuras, a escala musical, as calidades do son, a discriminación auditiva ou o establecemento de correspondencias de sons. Tamén se potenciaron as destrezas dos estudantes á hora de manipular os instrumentos e outros obxectos do seu contorno para producir os sons.

Así mesmo, logrouse traballar o corpo en relación co movemento, coas dimensións do espazo, as nocións temporais e o ritmo musical.

Descubriron que lles gustaba traballar deste xeito e, principalmente, víronse motivados ao facelo $\cos$ compañeiros e a través dos xogos musicais.

A participante valorou moi positivamente esta experiencia e comprometeuse a levar a cabo outras propostas que se lle fagan.

\section{Conclusións}

A unidade de ensino que se presentou céntrase no coñecemento de experiencias de aula reais que son planificadas de xeito interdisciplinar. Desde o momento da súa concepción, os investigadores trasladáronlle á profesora a intención de que os/as nenos/as debían participar, facer as actividades e aprender contidos de diferentes áreas curriculares simultaneamente.

Os comentarios da docente, ante o proceso e ante os resultados, indican que o alumnado comprendeu máis profundamente os diversos conceptos das materias, tendo a capacidade de os relacionar e favorecendo o progreso en todos os ámbitos educativos.

Por outra parte, os obxectivos deste estudo víronse cumpridos, pois logrouse salientar a importancia equitativa das dúas materias no desenvolvemento dos/as nenos/as, a súa capacidade formativa e traballar de forma interdisciplinar.

Hai moitos beneficios no traballo conxunto pois o alumnado ten unha visión global, e a educación musical non só axuda á comprensión de conceptos matemáticos, senón que favorece o progreso en todas as esferas da educación.

Este era só un exemplo das posibilidades que ten a combinación destas dúas materias. Con todo, as actividades e experiencias que podería deixar o binomio Educación Musical e Matemáticas son infinitas; todo depende da creatividade de profesores e alumnos, e da súa capacidade de se adaptar aos recursos proporcionados polo ambiente.

\section{Referencias}

Akoschky, J., Alsina, P., Díaz, M. \& Giráldez, A. (2008). La música en la escuela infantil (0-6). Barcelona: GRAO.

Barberá Saiz, J. (2012). Sistema de afinación musical de proporciones áureas. Trabajo final de Master. (Máster en Ingeniería Acústica). Valencia, Universidad Politécnica de Valencia.

Casals, A., Carrillo, C. \& González-Martín, C. (2014). La música también cuenta: combinando matemáticas y música en el aula. LEEME, 34, 1-17. http://musica.rediris.es/leeme/revista/casalsetal14.pdf

Chao-Fernández, R.; Mato-Vázquez, D. \& ChaoFernández, A. (2015). Actividades interdisciplinares de Matemáticas y Música para Educación Infantil. Vol. Extr., No. 6., 32-36.

DOI: $10.17979 /$ reipe.2015.0.06.123

Conde Caveda, J. L., Martín Moreno, C. \& Viciana Garófano, V. (2002). Las canciones motrices II: Metodología para el desarrollo de las habilidades motrices en Educación Infantil y Primaria a través de la música. Barcelona: INDE publicaciones.

Edo, M. (2012). Situaciones interdisciplinarias para el desarrollo del pensamiento matemático en Educación Infantil en la formación de maestros. En M. MarínRodríguez; N. Climent-Rodríguez (eds.), Investigación en Educación Matemática. Comunicaciones de los grupos de investigación. XV Simposio de la SEIEM (pp. 427-453). Ciudad Real: SEIEM.

Fernández-Carrión, M. (2011). Música y matemáticas: conexiones curriculares para un mayor éxito educativo. http://recursostic.educacion.es/artes/

Gómez, P. (2012). Matemáticas y música en niños pequeños. RSME (Real Sociedad Matemática Española). Universidad Politécnica de Madrid.

Levitin, D. (2011). Tu cerebro y la música. Barcelona: RBA.

Mankiewicz, R., (2000). Historia de las matemáticas. Barcelona: Paidós.

Pascual Mejía, P. (2006). Didáctica de la Música en educación infantil. Madrid: Pearson Pentice Hall.

Pastor Martín, A. (2008). Matemáticas en la Música. Suma, 59, 17-21.

https://revistasuma.es/IMG/pdf/59/017-021.pdf

Peralta Coronado, J. (2011). Modelos matemáticos del sistema de afinación pitagórico y algunos de sus derivados: propuesta para el aula. Educación Matemática. 23 (3), 67-90.

http://www.scielo.org.mx/pdf/ed/v23n3/v23n3a4.pdf

Tomasini. M.C. (2006). El fundamento matemático de la escala musical y sus raíces pitagóricas. Ciencia y Tecnología, Palermo: Universidad de Palermo, 6, 1528. 